\title{
Increasing Solidification Rate of M2 High-Speed Steel Ingot by Fusible Metal Mold
}

\author{
Yan-Liang $\mathrm{Ji}^{1} \cdot$ Wei Zhang ${ }^{1} \cdot$ Xiao-Yang Chen ${ }^{1} \cdot$ Jian-Guo $\mathrm{Li}^{1}$
}

Received: 9 December 2015/Revised: 12 January 2016/Published online: 15 March 2016

(C) The Chinese Society for Metals and Springer-Verlag Berlin Heidelberg 2016

\begin{abstract}
As one of the most popular used high-speed steels, M2 possesses excellent hardness and toughness as cutting tools. Networks of eutectic carbides distributing in the inter-dendritic region are academically considered to be the typical microstructure of $\mathrm{M} 2$, which can be refined by increasing cooling rate. In this paper, a novel casting method named fusible metal mold (FMM) is employed to refine the microstructure of M2 high-speed steel. Results show that FMM casting method can improve cooling rate by $100 \%$ without any contamination of the melts' composition.
\end{abstract}

KEY WORDS: Carbide; Cooling rate; Solidification process; Microstructure; Dendritic spacing

\section{Introduction}

High-speed steels are widely used in manufacturing cutting tools with high speed due to their excellent red hardness and wear resistance. Among them, M2 is one of the most popular one [1-3]. Traditionally, M2 high-speed steel manufacturing includes two steps, namely the mold casting and subsequent hot working like forging and rolling, which can break the coarse carbides network and refine structure $[4,5]$. Electroslag remelting is another popular process for manufacturing high-speed steel with improved solidification structures [6, 7]. Typical as-cast structure of M2 highspeed steel consists of dendrites surrounded by inter-dendritic network of eutectic carbides [1,2]. These carbides, however, are coarse and severely deteriorate the performances of M2 high-speed steel [2,3]. Thus it is essential to make the carbides refine and their homogeneity improve.

Available online at http://link.springer.com/journal/40195.

Jian-Guo Li

lijg@sjtu.edu.cn

1 School of Materials Science and Engineering, Shanghai Jiao Tong University, Shanghai 200240, China
Up to now, most researchers have focused on forging [3], heat treatment [8-11], and addition of alloy elements [12, 13], which can, to a certain extent, refine the carbides network and size, but few concentrate on the initial solidified process of M2 high-speed steel.

Improve cooling rate can acquire a series of excellent properties like finer microstructure, extended solid solubility, and improved strength [14, 15]. During casting, contact between the metal and mold wall is not so perfect that the heat transfer at the interface changes with time, creating a thermal contact resistance which impedes the heat transfer at the interface. Generally, thermal contact resistance can be divided into four stages [16, 17]. In brief, as melt spreads on the substrate and contact surface area increases, thermal contact resistance decreases continuously to a minimum level, and then with the melt solidifying and casting layer contracting from the mold, thermal contact resistance increases. When the solidified metal crust is thick enough, the contact at the interface reduces to a stabilized solid-solid contact, indicating the formation of air gap. So if the air gap is eliminated and metal contacts with the mold directly during the solidification process, the heat transfer can be faster.

Accordingly, we employed a novel casting method: fusible metal mold (FMM) casting. The key point of this 
method is that the mold is made of low melting alloy which can maintain solid state in the first few seconds after filling and fuses as soon as the casting layer forms. As a result, the melted mold can fill the air gap and keep the mold and ingot contacting with each other for a longer time, and thus boosting the heat transfer. Above all, we hope to use FMM to improve cooling rate and refine casting microstructure of M2 high-speed steel.

\section{Materials and Methods}

To ensure identical casting conditions such as pouring temperature, composition and size, the permanent metal mold (PMM) was divided into two parts: One side was a complete composition of H13 steel, while the other side was a 5-mm-thick aluminum alloy 6061 layer inside with H13 steel outside, and the total thickness was equal to the PMM side. The two parts were separated with steel plates in case that the liquid aluminum penetrates into the permanent mold air gap. Figure 1a illustrates the schematic representation of the mold used in this experiment. Ingot was made of AISI M2 high-speed steel with the composition (wt\%) of $0.92 \mathrm{C}, 6.17 \mathrm{~W}, 4.79 \mathrm{Mo}, 4.00 \mathrm{Cr}, 1.85 \mathrm{~V}$, $0.28 \mathrm{Si}$ and 0.34 Mn. Five-kilogram M2 high-speed steel was melted in a medium-frequency induction furnace under argon as protective atmosphere and poured into the mold. After solidification, the cylindrical ingot was sectioned along A-A direction (also shown in Fig. 1a) for direct observation. Long strip specimen was cut from the middle of the ingot and divided into four parts evenly with serial number 1-4 (Fig. 1b). The specimens were polished and then etched using $5 \mathrm{ml} \mathrm{42 \%} \mathrm{HF}+100 \mathrm{ml} \mathrm{30 \%} \mathrm{H}_{2} \mathrm{O}_{2}$ solution. The microstructures were examined by optical microscopy and scanning electron microscopes (SEM). Compositions of carbides were characterized using energydispersive spectrometer (EDS).

\section{Results and Discussion}

Figure 1b shows the macrostructure of M2 high-speed steel ingot, where the left side is from PMM and the right from FMM. A distinctive representation of higher solidification rate has been obtained by FMM casting, with central shrinkage cavity being deflective to the left at about onethird place across the ingot, which is a distinctive representation of higher solidification rate obtained by FMM casting.

Figure 2 is the microstructures of the as-cast M2 highspeed steel observed at 0,10 , and $25 \mathrm{~mm}$ below the ingot surface in both sides, respectively. As can be seen that the microstructure of M2 ingot consists of dendritic matrix with carbides distributed in the inter-dendritic region, showing a typical solidification microstructure of the steel $[1,2]$. Another phenomenon is that the microstructure of FMM side is much finer and the carbides distribute more homogeneously than PMM side, demonstrating that FMM casting method can improve cooling rate and refine ingot structure. To further explain this, we use the empirical relationship formula between cooling rate and secondary dendritic arm spacing $(d)$ as follows:

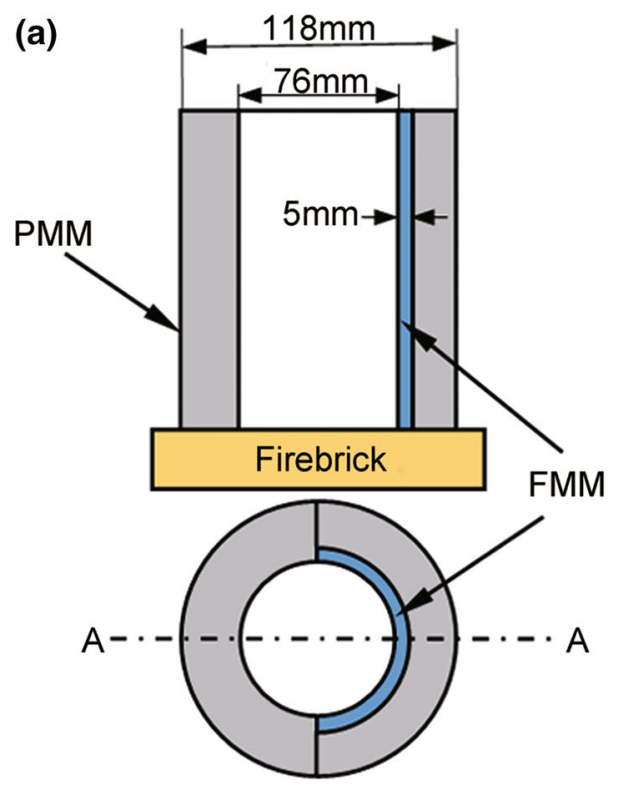

(b)

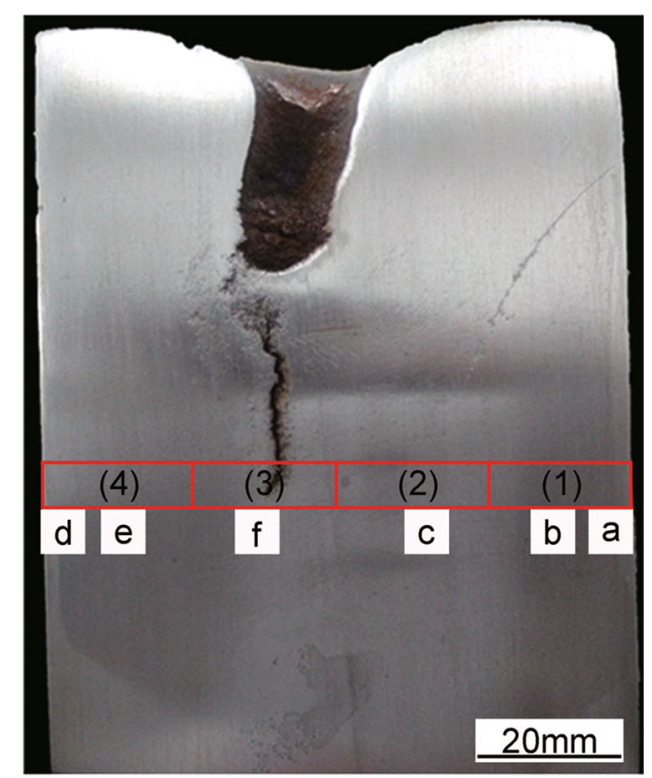

Fig. 1 a Schematic representation of the mold used and $\mathbf{b}$ macrostructure of the ingot, $\mathbf{a}-\mathbf{f}$ the microstructure locations observed by optical microscope 

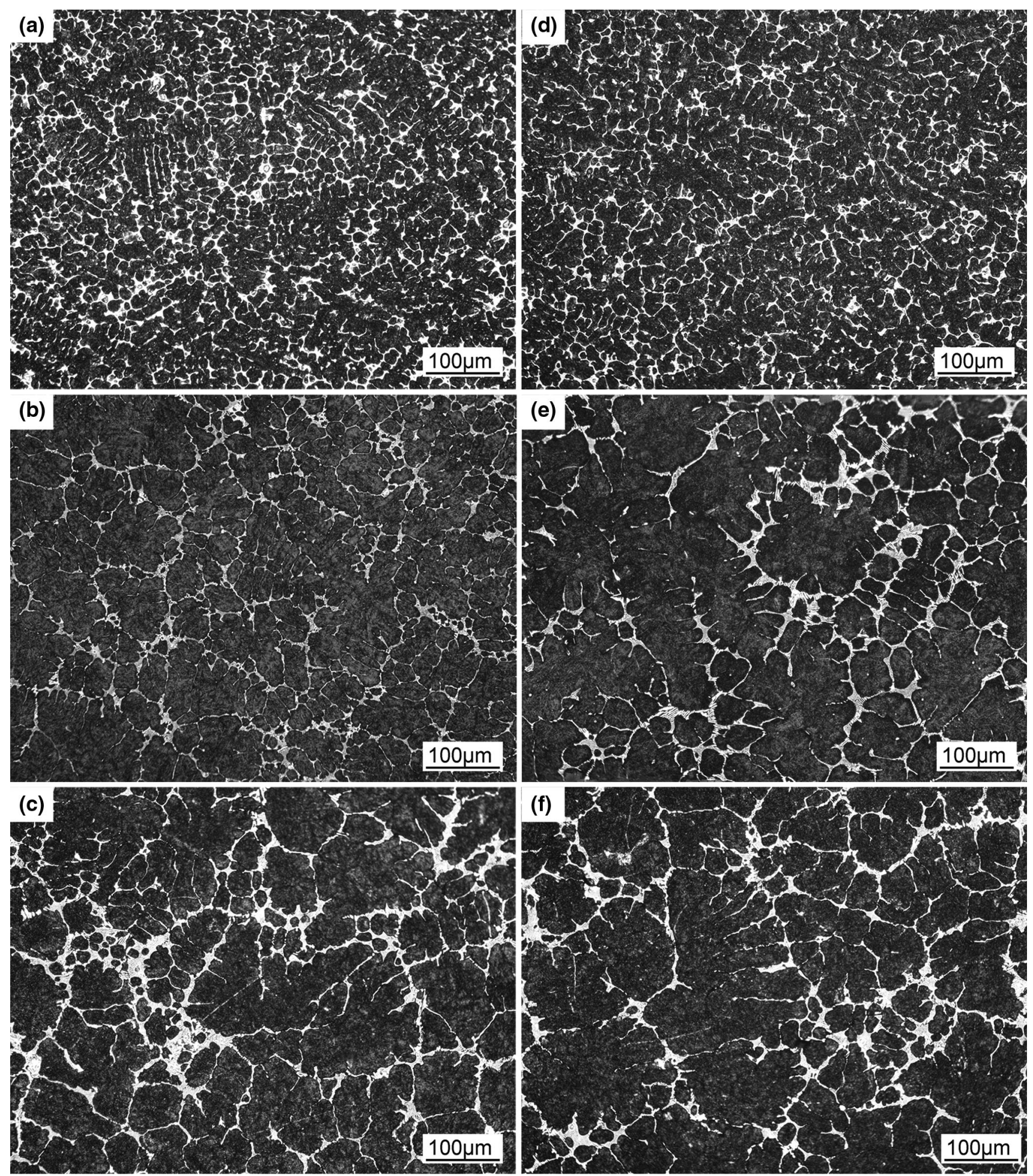

Fig. 2 Microstructures of the as-cast ingot made by FMM a, b, c, PMM d, e, f: a, d measured on the surface, b, e $10 \mathrm{~mm}$ under the surface, c, f $25 \mathrm{~mm}$ under the surface

$d=A(\mathrm{~d} T / \mathrm{d} t)^{-b}$

Where $A$ and $b$ are material-specific parameters, and $\mathrm{d} T /$ $\mathrm{d} t$ represents cooling rate. In our experiment, $A=32$, $b=0.28$ [1]. By measuring $d$ of the two parts with a deepness of $0,3,5,8,10,13,15,20,25 \mathrm{~mm}$ away from the surface, respectively, we can acquire a local cooling rate of the casting indirectly. As shown in Fig. 3, the cooling rate 


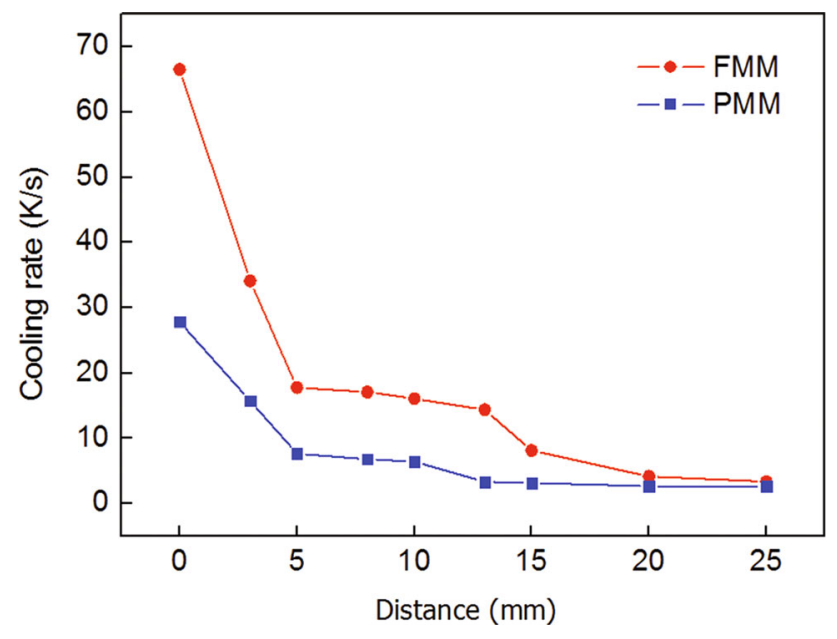

Fig. 3 Experimental cooling rate of the ingot obtained by FMM and PMM casting method

in both sides decreases gradually, but FMM side exerts a higher cooling rate, about twice that of PMM side.

Cooling rate is directly determined by the heat transfer, which relates to both the heat transfer capacity of the material and the heat transfer conditions at the metal-mold interface [14], the latter of which is influenced greatly by the air gap. During the initial period after the melt filling, the interface keeps liquid-solid contact well without air gap at the interface, and the heat transfer is mainly controlled by conduction. Due to a higher thermal conductivity $(162 \mathrm{~W} /(\mathrm{m} \mathrm{K})$, $294 \mathrm{~K})$ of aluminum alloy [18] than that of H13 steel (28.6 W/(m K), $473 \mathrm{~K})$ [19], FMM side obtains much higher cooling rate. As the melt cools and solidifies, heat transfers out continuously and the temperature of the mold rises quickly. When the temperature of FMM reaches the melting point of aluminum alloy $(918 \mathrm{~K})$, the thin layer is melted; meanwhile, the solidification layer has formed and the contracts from the mold. Consequently, the thin liquid layer of aluminum alloy offsets the casting contraction and sustains the contact between mold and casting, thus a relatively higher cooling rate is acquired. Figure 3 shows that the cooling rate of FMM side is about two times compared with PMM side, showing a platform. There are two reasons that may account for the increase in cooling rate. One is the higher thermal conductivity of aluminum alloy, and the other is the elimination of air gap layer between mold and casting. As shown in Fig. 1a, FMM is just a thin layer $(5 \mathrm{~mm})$ which is surrounded by $\mathrm{H} 13$ steel, heat still needs to be transferred by conduction into air through steel ultimately. Accordingly, we can infer that the increase of cooling rate is mainly the result of elimination of air gap. In addition, because $\mathrm{H} 13$ steel has relatively small thermal conductivity, with the mold temperature rising gradually and solidification layer forming, the cooling rate decreases gradually. In later examination, no evidence of formation of air layer was found between the ingot and both molds. And thus we can draw a conclusion that heat is transferred by conduction through aluminum alloy and still exerts higher cooling rate than permanent mold. During final period of solidification, mold temperature is extremely high and heat transfer between mold, and air becomes the chief factor that controls the cooling rate and makes it no difference to whether PMM or FMM. In general, FMM casting method can increase cooling rate by $100 \%$.

Figure 4 shows SEM images of eutectic carbide distribution in the inter-dendritic region $10 \mathrm{~mm}$ under the surface. Table 1 is the compositions of these carbides examined by EDS. The results show that the carbides in both sides have laminar morphology with laminar spacing about $0.5 \mu \mathrm{m}$ in FMM side and $1 \mu \mathrm{m}$ in PMM side. Closer examination reveals that the carbides in FMM side has complex regular laminar morphology and are separated by the matrix with smooth boundaries, while the carbides in PMM side has irregular laminar morphology and have no clear matrix boundary. Morphology change is accordance with Zhou's result by increasing cooling rate [2] and by continuous casting method [4]. Result of EDS indicates the main elements in the carbides are, except for molybdenum and tungsten, iron, vanadium, and chromium. Analyses of the carbides morphology and main elements reveal the carbides as $M_{2} \mathrm{C}$ type, typical eutectic carbide in M2 highspeed steel. Researches have proved that the morphology of $M_{2} \mathrm{C}$ eutectic is substantially influenced by various factors including chemical composition, cooling rate, and minor additions of certain elements such as aluminum and nitrogen [1], while complex regular $M_{2} \mathrm{C}$ is a representative of high cooling rate [20-22]. This, in turn, demonstrates that FMM indeed improves cooling rate and refines material structure.

Another important issue that we have to concern in FMM casting method is that whether the melt aluminum will mix with the casting melt, having the performance of ingots be impaired. To confirm this, element content, especially aluminum, was measured by line scanning from the surface of the ingot on FMM side. Result shows (in Fig. 5) only minute quantity of aluminum exists in the ingot within a depth of about $250 \mu \mathrm{m}$, including the melting aluminum cling to the solidified layer due to solid diffusion, but this can be easily removed in the later manufacturing process.

\section{Conclusions}

In our research, we exploited a novel casting method for M2 high-speed steel: fusible metal mold (FMM) casting. A thin layer of metal or alloy with low melting point is added 

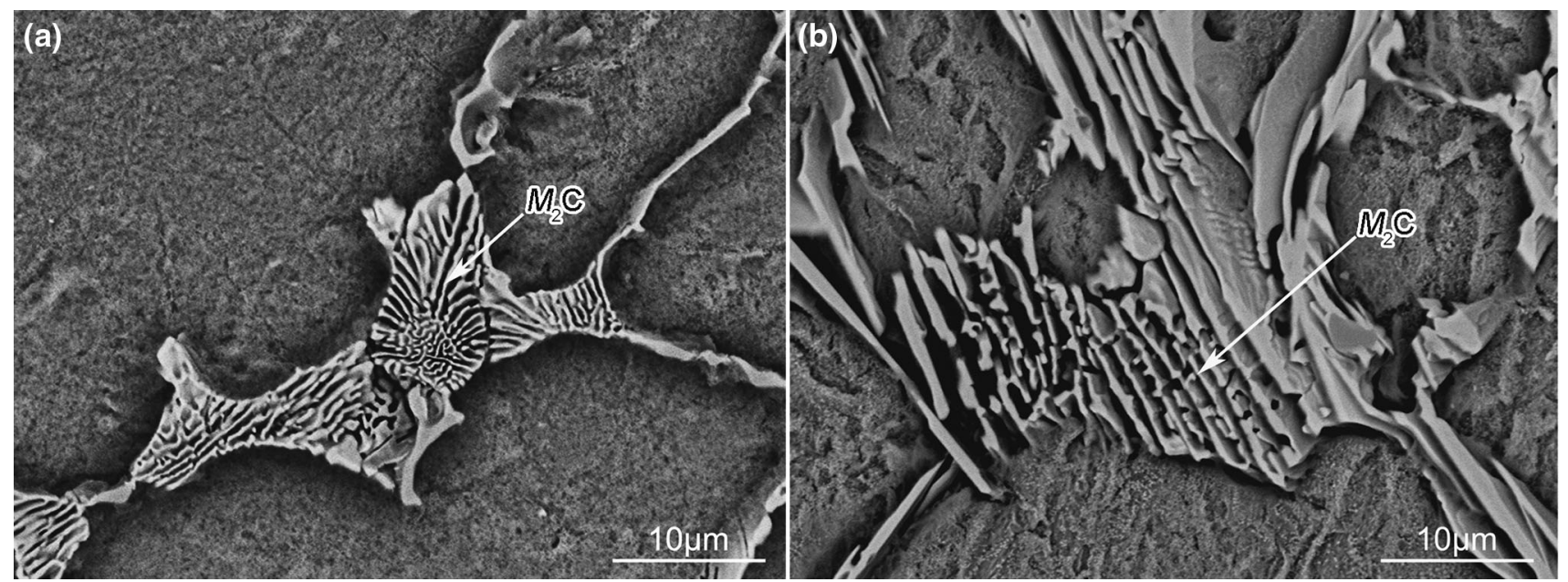

Fig. 4 SEM images of $M_{2} \mathrm{C}$ at $10 \mathrm{~mm}$ under the ingot surface: a FMM side, b PMM side

Table 1 Compositions of eutectic carbides in M2 high-speed steel (at.\%)

\begin{tabular}{lllllrr}
\hline Examine region & C & V & Cr & Fe & Mo & W \\
\hline FMM & $35.2 \pm 0.1$ & $8.4 \pm 0.1$ & $7.5 \pm 0.1$ & $5.1 \pm 0.1$ & $15.8 \pm 0$ & $28.0 \pm 0.3$ \\
PMM & $61.2 \pm 0.1$ & $6.1 \pm 0.1$ & $3.3 \pm 0$ & $2.9 \pm 0.2$ & $8.4 \pm 0$ & $18.0 \pm 0.4$ \\
\hline
\end{tabular}

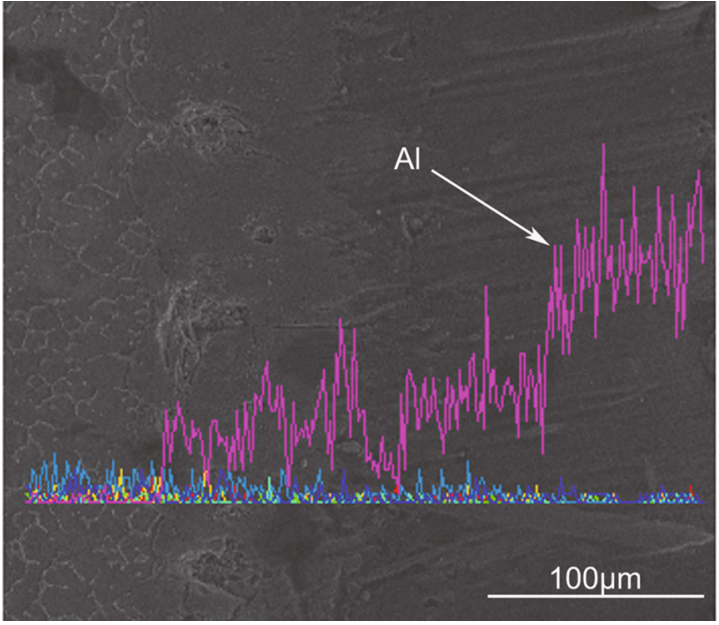

FMM side

Fig. 5 Aluminum content examined from the surface of the ingot on FMM side

in the inner side of traditional permanent mold. This layer was melted after the forming of solidification layer and substitutes the air gap resulting from the mold expansion and casting contraction between the cast and mold. As a consequence, an average cooling rate was increased as much as $100 \%$, without any contamination of the original composition of the steel by the melting layer or change of the inter-dendritic carbides type. Ingots with much finer microstructure and homogeneously distributed carbides were obtained. To sum up, FMM casting method can serve as a reference for improving cooling rate and new material manufacturing.

Acknowledgments This work was financially supported by National Basic Research Program of China (No. 2011CB12900) and National Natural Science Foundation of China (No. 51204106).

\section{References}

[1] M. Boccalini, H. Goldenstein, Int. Mater. Rev. 46, 92 (2011)

[2] X.F. Zhou, F. Fang, J.Q. Jiang, W.L. Zhu, H.X. Xu, Mater. Sci. Technol. Lond. 30, 116 (2014)

[3] M.G. Qu, S.H. Sun, X.H. Bai, Z.P. Shi, Y. Gao, W.T. Fu, J. Iron. Steel Res. Int. 21, 60 (2014)

[4] X.F. Zhou, F. Fang, J.Q. Jiang, China Foundry 8, 290 (2011)

[5] P.D. Ding, C.D. Zhang, B. Jiang, S.Z. Zhou, Iron Steel 41, 63 (2006)

[6] S.H. Suh, J. Choi, T. Iron Steel I. Jpn. 26, 305 (1986)

[7] M. Murgaš, A.S. Chaous, A. Pokusa, M. Pokusová, ISIJ Int. 40, 980 (2000)

[8] F. Cajner, V. Leskovšek, D. Pustaić, Key Eng. Mater. 592-693, 680 (2014)

[9] J. Arias, M. Cabeza, G. Castro, I. Feijoo, P. Merino, G. Pena, Weld. Int. 27, 1 (2013)

[10] M.C. Huang, C.H. Gao, L.G. Huang, Acta Metall. Sin. (Engl. Lett.) 16, 524 (2003)

[11] S.S. Gill, J. Singh, R. Singh, H. Singh, J. Mater. Eng. Perform. 21, 1320 (2012)

[12] A.S. Chaus, Mater. Sci. Technol. Lond. 30, 1105 (2014) 
[13] Y.L. Li, Q.C. Jiang, Y.G. Zhao, Z.M. He, X.Y. Zhong, J. Rare Earth 18, 134 (2000)

[14] L. Zeng, W. Zhang, Y.L. Ji, Y.J. Huang, J.G. Li, Metall. Mater. Trans. A 46, 2819 (2015)

[15] S. Shao, Y. Liu, C.S. Xu, Y.X. Xu, B. Wu, X.S. Zeng, X.F. Lu, X.J. Yang, Acta Metall. Sin. (Engl. Lett.) 28, 7 (2015)

[16] T. Loulou, E.A. Artyukhin, J.P. Bardon, Int. J. Heat Mass Tran. 42, 2129 (1999)
[17] M. Trovant, S. Argyropoulos, Metall. Mater. Trans. B 31, 75 (2000)

[18] M.R. Karimi, M. Sedighi, D. Afshari, Int. J. Adv. Manuf. Technol. 77, 885 (2015)

[19] K.A. Chiang, Y.C. Chen, Mater. Lett. 59, 1919 (2005)

[20] H. Fredriksson, S. Brising, Scand. J. Metall. 5, 268 (1976)

[21] H. Fredriksson, M. Nica, Scand. J. Metall. 8, 243 (1979)

[22] P.D. Ding, G.Q. Shi, S.Z. Zhou, Mater. Charact. 29, 15 (1992) 